\title{
WHATSAPPENING OUTSIDE YOUR LMS? ANALYZING A SOCIAL MEDIA INSTANT MESSAGING POWERED LEARNING COMMUNITY
}

\author{
Luciana Oliveira ${ }^{1}$, Alvaro Figueira ${ }^{2}$ \\ ${ }^{1}$ ISCAP / IPP Polytechnic of Porto \& CRACS INESC TEC (PORTUGAL) \\ ${ }^{2}$ University of Porto \& CRACS INESC TEC (PORTUGAL)
}

\begin{abstract}
The use of Social Media applications in educational settings has gained attention ever since educators became aware of their growing role in student's daily routine. These arise as privileged tools for social interactions, information exchange, collaborative knowledge building, immediate communication and persistent attention retaining, among others. Consequently, these tools impose themselves as complements to the profoundly established use of the traditional LMS, either being propelled by educators or requested by students.
\end{abstract}

In previous research, we have already identified Facebook groups as one of the social media applications with the highest potential to foster the development of social learning communities. We have acknowledged the need to integrate Facebook groups and corresponding learning analytics into formal learning environments, such as the institutional LMS, and we have developed and presented a system which performs that integration.

However, as the educational settings diversify in terms of pedagogy, coursework and student's profile and cultural background, we have identified the need to extend this integration to other social media tools, such as the instant messaging app WhatsApp, and to provide valuable learning analytics on its usage. Mobile, instant messaging based learning communities differ a lot from forum-alike communities, where threads, topics, conversations and interactions are easily trackable and, for instance, social network analysis can be conducted to profile members, roles and relationships.

Therefore, research presented in this paper adds to previous consolidated work both on the technological and analytical dimensions. We address the challenges posed by the integration of WhatsApp based learning analytics in the LMS Moodle, starting by the fact that, unlike Facebook groups, WhatsApp does not provide an API for developers, nor any stream of structured data that can feed a real-time monitoring system.

We then focus research on revealing an actual set of visual learning analytics that characterize a learning community of about thirty foreign master students, who used WhatsApp as a complementary tool during a semester. We discuss which type of learning analytics and corresponding visualizations best suit WhatsApp learning communities; what can educators draw from the analytics of such communities; and how that information can strengthen student assessment and profiling.

Keywords: WhatsApp, learning analytics, learning communities, mobile learning, LMS

\section{INTRODUCTION}

Social media has been raising new educational, pedagogic and social drivers that heavily impact the way teachers use and aggregate learning environments and on the way that students interact and learn.

Traditionally, most internal and distance learning higher education institutions adopt learning management systems (LMS) to deliver online learning. Nowadays, however, many students use social networks to share information, discuss topics or concepts, and cooperate to complete homework assignments or term projects. Social media provides convenience and speed in peerto-peer exchange of knowledge and collaboration, which seems to be a preferred method of learning. This new learners' profile and behaviours encourages self-learning and represents a 
significant driving factor for a shift from the traditional teacher-centred learning to student-centred learning [1].

The Horizon report for Higher Education [2] states that "Many educators are discovering that online platforms can be used in order to provide the solution to problems in groups, and to develop communication skills whilst the students' knowledge is increased".

When referring to mobile instant messaging system (MIM), several authors $[1,3]$ state that chatting and discussion and for file sharing is becoming common among university students, and this positively affects knowledge sharing and impact student learning. In fact, the is a clear enhancement of the relationships between collaboration supported by social networks and motivation to learn, and between the willingness to share knowledge and the self-efficacy for learning and knowledge building.

The MIM WhatsApp, has seen a dramatic growth, with reports suggesting an increase of up to 1 million users per day, reaching a number of 600 million users in 2014 with a daily engagement higher than the industry standard [4], and its educational use is no exception to this rule.

However, the use of social media platforms is still not formally linked to the mandatory use of the institutional LMS and are frequently seen as recreational instruments. This lack of formal articulation between systems poses real challenges to educators trying to formally manage, account for, validate and measure the value of social media supported learning.

In order to address these needs we have been developing research related to the management of educational communication on social media and to the integration of social media platforms and tools in the institutional LMS, providing teachers with valuable learning analytics and the ability to better manage the multiplicity of learning environments.

In this paper, we begin by briefly referring to previous research outputs regarding the theoretical and technological foundations of the work we have been developing, namely in integrating Moodle and Facebook groups. We then focus on a case study conducted on a MSc with international students, where the MIM WhatsApp is used as the main complement to the Moodle platform. We bring forward some of the analytics we believe to be relevant for teachers and the results of a survey conducted among the students involved, in order to provide evidence on the educational and social value of the use of WhatsApp.

\section{PREVIOUS WORK}

The work presented in this paper builds on theoretical and technological foundations established in previous research, namely the Social Student Relationship Management (Social SRM) [5] framework and the EduBridge Social system [6].

\subsection{Social Student Relationship Management}

The first, consists of framework aimed at systematizing and analysing the relationship between educational providers (such as schools, universities and training centres) and students in social media environments. The Social SRM framework is aimed at amplifying the formal and informal bonds between students and schools, expanding their interactions into social conversations, and strengthening educational ties through the development of collaborative conversations, thus providing mutually beneficial value and ultimately, allowing for the growth of social and educational communities.

The framework is composed by three main communication domain areas:

- Teaching-learning communication

In this domain communication serves as a vehicle for reaching educational goals. It encompasses formal educational communication, which is sustained by a curriculum and pedagogic model with clear indications of contents, methods, requirements and assessment, and the informal educational communication, which is not institutionalized, methodical, structured, intentional and sustained by a previous definition of pedagogic goals. Informal educational communication is more prone to social media environments, thus it's important to understand that the absence of a curriculum and pedagogic model doesn't annul its educational potential. The spontaneous, simple 
conversation and group discussion that characterizes informal communication may produce educational effects, when contributing to behavioral changes in individuals.

- Classroom administration

This domain is in direct dependency of the organizational administrative communication that regulates learning tasks, schedules and procedures. Social media has proven to be an excellent tool for classroom administration, in terms of processes clarification and celerity, student responsiveness and time economy. This is heavily sustained by the amount of time and attention students dedicate to social media.

- Student social integration

This dimension is aimed at fostering the formation of the sense of belonging and ultimately the development of a learning community. It consists of the purest form of social interaction, relying heavily on the establishment of meaningful conversations that allow for the development of social and emotional bonds. From the teachers' point of view, and as a community builder/manager, it requires an engaging, motivational, cooperative and personal/informal communication approach that is favoured in social media environments.

Educational Social SRM comprises a set of communication domains that aim to foster student integration and avoid disengagement or dropout. It contributes to setting a welcoming school climate prone to success and completion, which has been defined as "...the quality and character of school life experiences and reflects norms, goals, values interpersonal relationships, teaching, learning and leadership practices, and organizational structures" [7]. For instance, in a blended learning environment, social media provides two-way exchanges between the classroom and the virtual interaction environment in the relationship building process - both environments being interchangeably reinforced.

\subsection{The EduBridge Social system}

Together with current Learning Management Systems (LMS), social networks have been providing teachers with knowledge and data on students' performance and pedagogy, both of formal and informal nature. This opens up possibilities to significantly increase the potential to make use of this data to improve learning outcomes and to provide instructors with informed decision making tools that can benefit teaching-learning contexts $[8,9]$.

In order to address the current needs of teachers and organizations to access, collect, organize, display and translate educational data developed the EduBridge Social system [6], which consists on a system that integrates Learning LMS and Social Networks.

The system's main purpose consists on capacitating the LMS, (namely Moodle) with features that, not only provide the appropriate integration of social networks' interactions and data inside the LMS, but also to provide teachers, organizations and students with integrated learning analytics obtained by collecting, organizing and visually displaying formal and informal data retrieved from social media.

This integration is fundamentally based on linking Moodle with Facebook Groups [10], thus EduBridge Social dynamically incorporates and displays, in Moodle, the analytics gathered from the interactions developed in a predefined Facebook group or set of groups. This configuration aims at providing educators with the necessary convenience and usability in the management of disconnected learning environments, by integrating them in a complementary functional relationship.

However, as the educational settings diversify in terms of pedagogy, coursework and student's profile and cultural background, we have identified the need to extend this integration to other social media tools, such as the instant messaging app WhatsApp, and to provide valuable learning analytics on its usage.

\section{METHODOLOGY}

In order to assess the social and academic value of the use of WhatsApp we used both a quantitative and qualitative methodology, built on the combination of the analysis of the logs extracted from the app and a survey applied to the course participants. 
The communication features of the traditional LMSs, such as Moodle, do not offer the potential of immediacy that the current profile of students requires from the interaction they maintain with teachers and peers. In this case, students were offered the possibility to use Facebook groups, which we had proved to be a valuable tool in terms of complimentary communication and interaction tool, or WhatsApp. The use of WhatsApp consisted of a unanimous choice among students, thus a group was created as a complimentary tool for communication and interaction with the teacher and among students.

The group under research was composed by 33 users (including the teacher). The course (MSc) was held at a Portuguese higher education institution, but all the students were Brazilian, and attending the course in distance learning. Also, students were not limited to the nature, type and timing of the conversations introduced in the WhatsApp group created to support the learning activities conducted on the course, which provided them with total freedom regarding any of the subject brought up, namely the ones identified in section 2.1: teaching-learning communication, classroom administration and social integration.

As previously stated we had already developed a system to integrate Facebook groups into Moodle's dashboard, but there wasn't (and there still isn't) any available integration system between Moodle and WhatsApp. While Facebook provides and API for integration with other systems, data collection of WhatsApp interactions can only be obtained by exporting the logs in plain text format (CSV), thus these were treated and compiled for analysis outside the LMS.

The timeframe comprised in this case study includes the conversations held during approximately three months (November to January), during the winter semester of the 2016/2017 school year.

\section{RESULTS}

In this next section we present results obtained by the analysis of WhatsApp logs and the students' perceptions on the value of WhatsApp for academic and social interaction.

\subsection{WhatsApp analytics}

Throughout the ninety-one days of interaction 4168 messages were produced among students and the teacher, being that $3 \%$ of those messages consisted of media messages containing either images, audio recordings or videos. For the purpose of the analysis we are only considering the text messages that emerged on the conversation (4058 messages), which consists on the group exchanging, on average 45 messages per day.

As illustrated in Fig. 1 (a), it is possible to observe that the number of messages posted by participants varies from 1 (min.) to 276 (max.), with two outliers identified (833 and 795 messages). Around half of the participants have introduced from 40 up to 155 messages, with a total average of 122 per participant.

The outliers identified in Fig. 1 (a) consist of a student (833 messages) and the teacher (795 messages).

Concerning the message length, as it is possible to observe in Fig. 1 (b), the minimum ranges from 14 characters up to 79 , with a total average of 41 characters per message. Around half of the messages are composed by 26 up to 48 characters long. There is, however, an outlier (User 32 ) with a message's average length of 192 characters. These messages were produced by one single user and concern to the lack of administrative support (complaints) given by the higher education institution in the resolution of enrolments in courses, tuition payments and access to administrative management resources.

Considering these tow indicators, it is possible to conclude that there is one student in particular, who is very active / responsive and that the teacher plays a very relevant role in the community. Looking at the content of the messages posted during this period both the teacher and the student (identified as outliers) represent the linking elements that answer the group's questions, provide feedback and instructions and arise relevant questions, particularly in the domain of classroom administration (for the teacher) and social integration (for the student). 


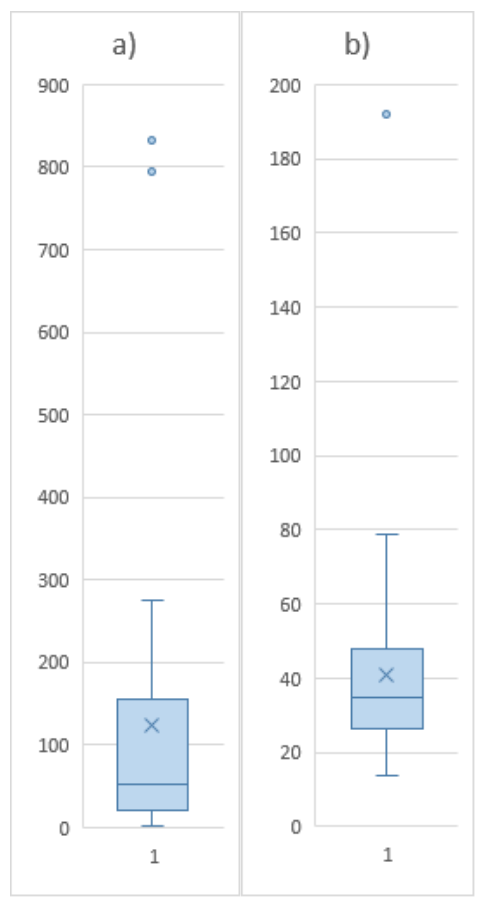

Fig. 1: (a) Number of messages and (b) average message length

Refining this analysis, for both academic and social purposes, it is important for the teacher, as well as for the students, to be able to identify who are the most active participants on the network, i.e., the students that posted more messages than the total computed average, which we have previously identified. This information is depicted in Fig. 2.

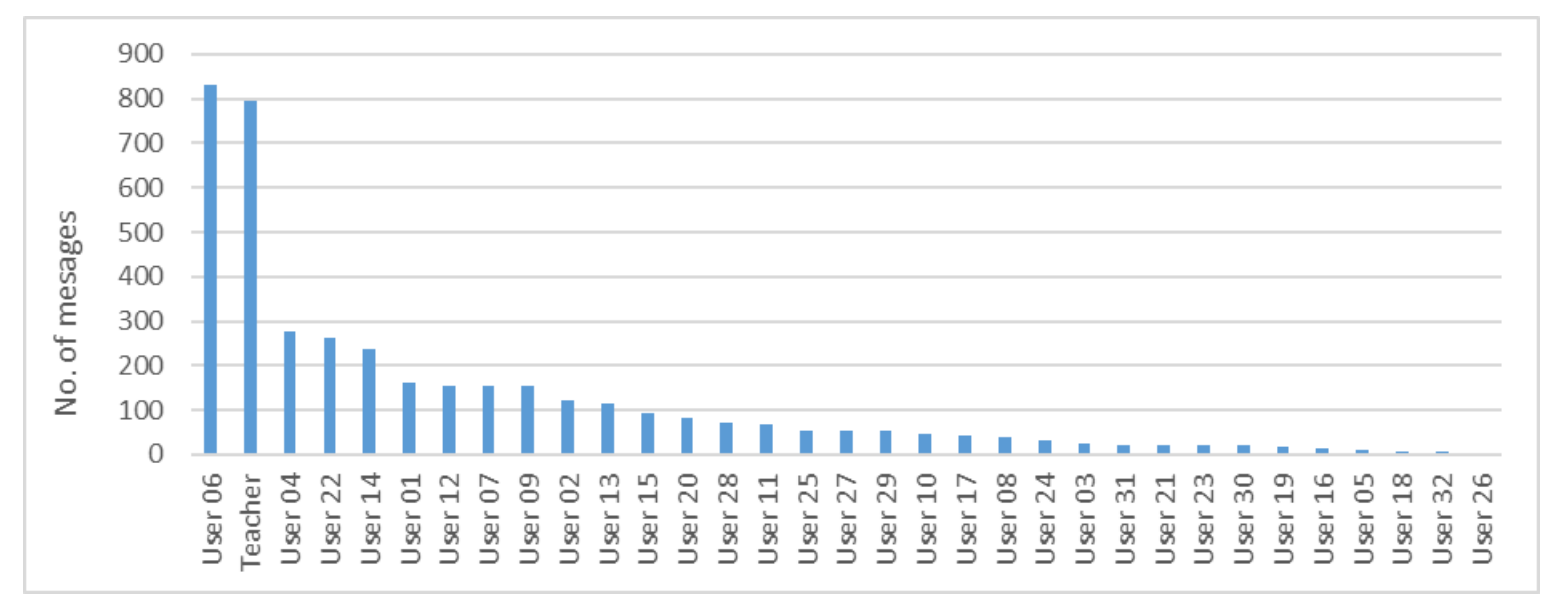

Fig. 2: Most active users

As it is possible to observe there are 8 students who posted a total number of messages that are above the total average, together with the teacher. These can be considered as the participants who are typically more involved in discussions, either in introducing conversation topics, asking for assistance in learning activities and access to resources or answering peers.

Concerning the total number of messages posted by students and teacher, the teacher actually ranks fifth, which means that there are four students propelling discussions and answering questions while the teacher acts as a relevant mediation element, but not the focal one.

In what the temporal analysis is concerned, we considered the number of messages per hour of the day and per day of the week, as illustrated in Fig. 3 a) and b): 


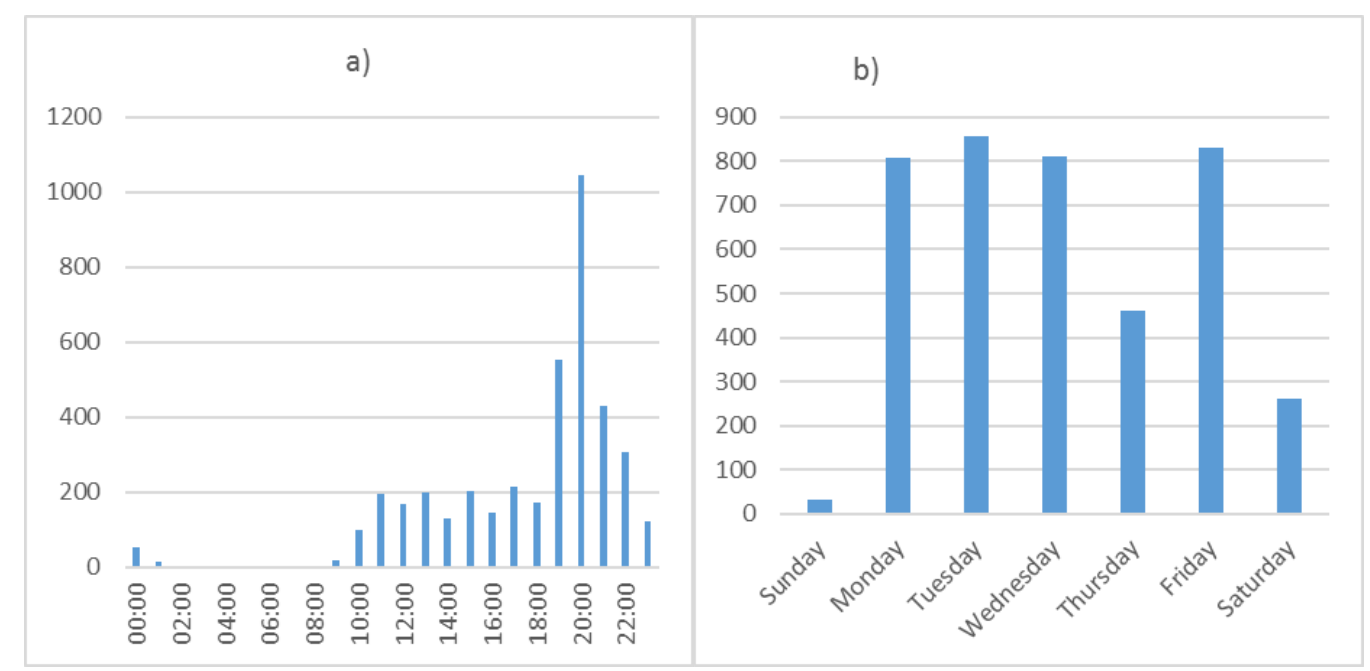

Fig. 3: a) no. of messages per hour of the day; b) no. of messages per week day

The most prolific hours of the day for emerging messages in the community range from 19:00 to $21: 00$, which is coherent with the profile of working students. Though they tend to interact during the afternoon, posting from 1 to 200 messages, it is after working hours that they are more available to devote time to attend distance learning classes and to undertake learning activities.

In terms of intensity of interactions per week day, Monday, Tuesday, Wednesday and Friday are the most relevant days. The low number of messages posted in Thursday, when compared to the remaining working days, is due to the fact that students had no classes in that day. Still, as it is possible to observe in Fig. $3 \mathrm{~b}$ ), students used some free time on Saturdays to devote to learning activities and catch up with the week's classes.

When considering the frequency of response, we have computed the time intervals between the messages posted on the group, which are illustrated in Fig. 4.

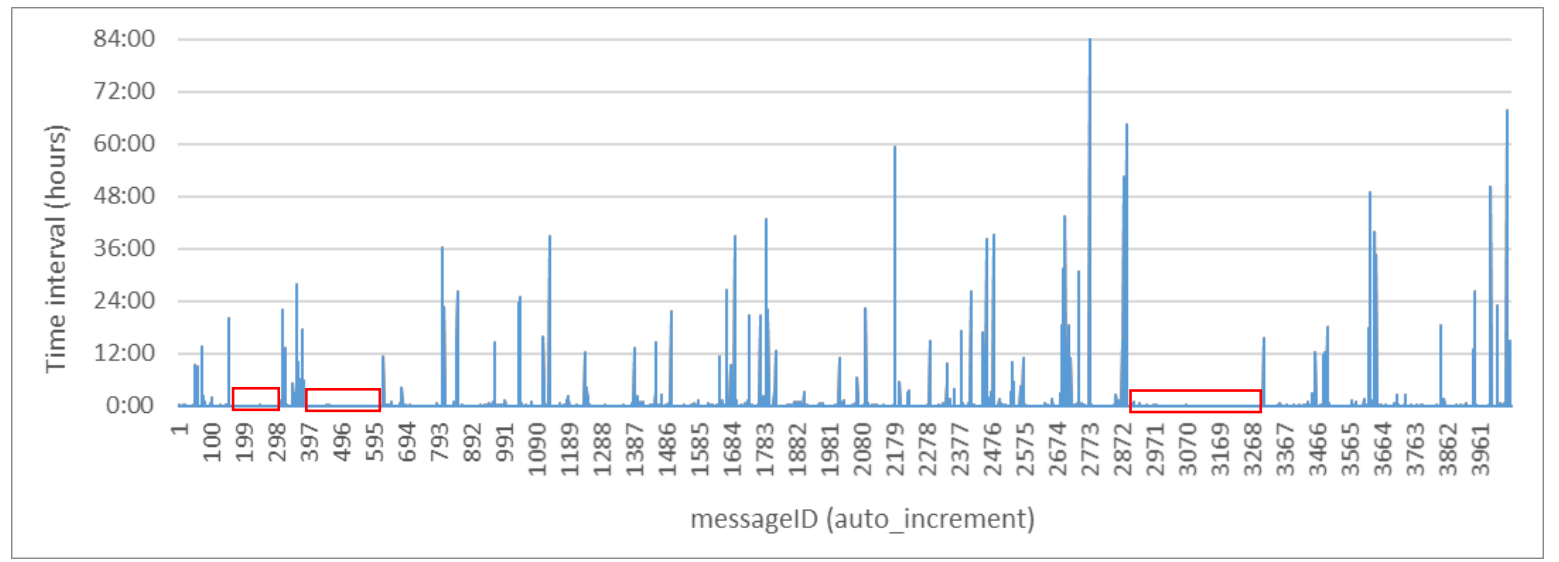

Fig. 4: Intervals between messages (evolution in minutes / hours)

Since the timeframe is too wide to present in more detail, the bigger intervals of time between discussion are more evident in Fig. 4, than the smaller time intervals. However, $96 \%$ of the messages exchanged between participants occurred in time intervals that range from 0 (zero) seconds to $1 \mathrm{~h}$ (examples are marked in the red rectangles in Fig. 4) and $1 \%$ of the messages occurred in time intervals that range from $1 \mathrm{~h}$ to $2 \mathrm{~h}$. The remaining $3 \%$ of messages occurred in time intervals that range from more than $2 \mathrm{~h}$ up to a maximum of $84 \mathrm{~h}$ ( 3,5 days).

Given this information we can conclude that this is a very active learning community with high density of interaction (small intervals between messages), which can be indicative of a very cooperative community. 


\subsection{Student's perceptions on the use of MIM in educational context}

In order to capture the students' perception on the social and academic value of the use of WhatsApp a survey was conducted at the end of the winter semester. Results presented in this subsection are based on the survey responses, which $61 \%$ of the students have provided.

The sample is composed by $60 \%$ female students and $40 \%$ male students, with ages comprised between 27 and 58 years old. The average age of the respondents is 44 years old.

Regarding the profile of the students, most of them (70\%) were not new to undertaking distance learning courses and they were very familiarized with the app WhatsApp. In fact, $95 \%$ of the students report on using the app more than five times per day in order to maintain contact with: co-workers, friends, family, classmates, teachers and services, such as, the doctor, the bank, the lawyer, the veterinary, etc. Students also indicated to be familiarized with other social networking platforms, such as Facebook (mentioned by $100 \%$ of the students), Instagram and Twitter.

As far as the interaction with teachers is concerned, while undertaking the MSc, students indicated to maintain regular contact with 1 (95\% of the students) up to 3 teachers, which leads us to conclude that the WhatsApp group under analysis might be the only one that students had at their disposal during the semester.

Students were questioned about the social dimension of the relationships they maintain or would like to have with their teachers. In the context of our research the social dimension of the relationships between the students and the teacher are of high relevance, since they are essentially supported by a social media app. Regarding this subject, students were asked to demonstrate their level of agreement with the following:

a) "I believe that a good social relationship between the teacher and the student is fundamental for my educational success";

b) "I believe that my teachers are not very committed to develop better social relationships with me (online and offline)";

c) "I would like my teachers to be more committed to develop better social relationships with me";

d) "I believe that the relationship between the teacher and the student should be restricted professional".

Results presented in Fig. 5 indicate that not only students value the social relationships that they maintain with teachers, but they also believe that they are fundamental for the accomplishment of their learning goals.

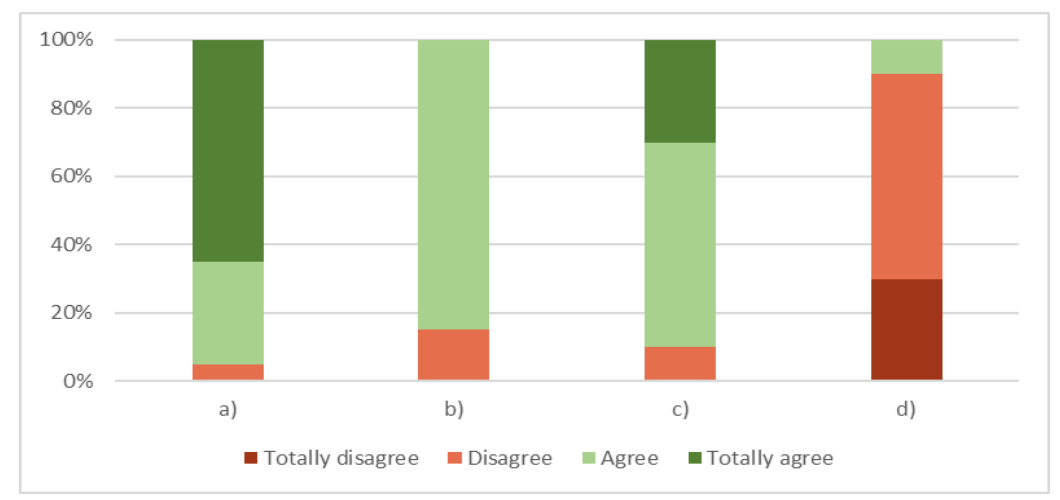

Fig. 5: Levels of agreement / disagreement with issues related to social relationships with teachers

Concerning the educational value of the WhatsApp group and of the relationships established among peers, students were asked to demonstrate their level of agreement with the following:

a) "I believe that the WhatsApp group adds value to the Moodle course page";

b) "I would rather use the Moodle course page exclusively";

c) "I find it confusing to have a Moodle course page and a WhatsApp group simultaneously"; 
d) "I believe that the WhatsApp group allows me to have a better social relationship with my classmates";

e) "I believe that the WhatsApp group allows me to have a better working relationship with my classmates";

f) "I feel that in the WhatsApp group the class functions as a cooperative team";

g) "I believe that WhatsApp group helps me to better keep up with the course learning activities";

h) "I believe that the WhatsApp group makes me feel more motivated to undertake the course;

i) "In the WhatsApp group I feel that I am a more active participant in managing the proposed learning activities and my personal interests";

Results presented in Fig. 6 indicate that MIM is a valuable tool as a complement to the Moodle course page and most of the students don't believe that it is confusing to use both systems simultaneously. Results also demonstrate the MIM has a positive impact on the ability to manage coursework and motivation to learn.

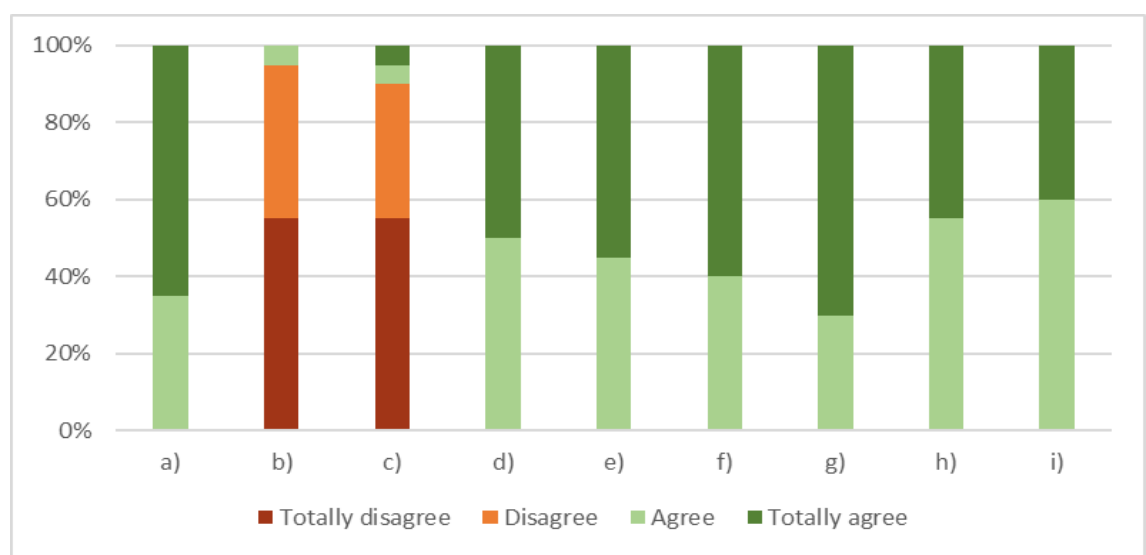

Fig. 6: Levels of agreement / disagreement with issues related the educational value of the WhatsApp group and of the relationships established among peers

As for the relationships with peers, students also report on positive impacts of the use of WhatsApp on their social and working relationships, on their potential to feel more actively participating and involved and on the development of cooperative bonds, which are central to the development of a learning community with high sense of belonging, which are also recognized by [11].

As the most positive aspects of using MIM students refer to: a more intensive, efficient and agile communication and interaction with the teacher and peers (addressed by [12]); the ability to clarify doubts more quickly either with the help of the teacher or the classmates; a more active participation; the ability to exchange experiences with peers; the increase in trust and motivation; the development of a more harmonious environment and the ability to spare the time that the teacher spends in answering the same question over and over.

As the most relevant disadvantages, students refer to: peers bringing up subjects of conversation that are not relevant for the purposes of the community; information overload and difficulty to keep up with the MIM flow; messaging during inconvenient hours / moments by of the day and becoming addicted to MIM (both address by [13]).

However, on a final remark, the totality of the students has indicated that they would like to maintain a regular interaction with other teachers of the MSc, because they believe that the benefits are surpass the identified limitations.

\section{CONCLUSIONS AND FUTURE WORK}

In this paper we have provided analytics that we believe to be relevant for teachers and the results of a survey conducted among the students involved, in order to provide evidence on the 
educational and social value of the use of WhatsApp. This work is preceded by theoretical and technological foundations which have been validated among the academy and consist on the first step to address and integrate an additional social media tool to the widely adopted LMS Moodle.

However, the research presented is not without limitations and should not be considered as an end in itself. The analysis of the presented results have allowed us to better perceive the challenges that we face in terms of technological integration with Moodle and on the type and usefulness of the presented analytics, which need improvement. As far as the integration with Moodle is concerned, we still have to overcome the fact that WhatsApp does not provide an API for integrations with other systems, both for managing the MIM system and for the elaboration of more consistent and informative analytics. Therefore, technical future work needs to address these aspects in order to provide solutions for these challenges.

We believe, however, that we have contributed to the validation of WhatsApp groups as a relevant social and academic complementary tool and that the results brought forward by the students' perceptions of its usage may sustain other present, undergoing and future research in the domain of MIM for educational purposes.

\section{ACKNOWLEDGEMENTS}

This work is supported by the ERDF - European Regional Development Fund through the COMPETE Programme (operational programme for competitiveness) and by National Funds through the FCT (Portuguese Foundation for Science and Technology) within project «Reminds/ UTAP-ICDT/EEI-CTP/0022/2014».

\section{REFERENCES}

[1] Eid, M.I.M. and I.M. Al-Jabri, Social networking, knowledge sharing, and student learning: The case of university students. Computers \& Education, 2016. 99: p. 14-27.

[2] Johnson, L., et al., Horizon Report Europe: 2014 Schools Edition. Luxembourg: Publications Office of the European Union, \& Austin, Texas: The New Media Consortium, 2014.

[3] Barhoumi, C., The Effectiveness of WhatsApp Mobile Learning Activities Guided by Activity Theory on Students' Knowledge Management. Contemporary Educational Technology, 2015. 6(3): p. 221-238.

[4] Forbes. WhatsApp Hits 600 Million Active Users, Founder Says. 2014 5th January 2017]; Available from: http://www.forbes.com/sites/parmyolson/2014/08/25/whatsapp-hits-600million-active-users-founder-says/.

[5] Oliveira, L. Social Student Relationship Management in Higher Education: extending educational and organisational communication into Social Media. in 9th Annual International Technology, Education and Development Conference. 2015. Madrid, Spain: IATED.

[6] Oliveira, L. and Á. Figueira. EduBridge Social: Bridging Social Networks and Learning Management Systems. in 8th International Conference on Computer Supported Education: CSEDU. 2016. Italy: Scitepress.

[7] Bryant, V.C., et al., School as haven: Transforming school environments into welcoming learning communities. Children and Youth Services Review, 2013. 35(5): p. 848-855.

[8] Baker, R.S. and P.S. Inventado, Educational data mining and learning analytics, in Learning analytics. 2014, Springer. p. 61-75.

[9] Siemens, G. and R.S. d Baker. Learning analytics and educational data mining: towards communication and collaboration. in Proceedings of the 2 nd international conference on learning analytics and knowledge. 2012. ACM.

[10] Wang, Q., et al., Using the Facebook group as a learning management system: An exploratory study. British Journal of Educational Technology, 2012. 43(3): p. 428-438.

[11] Fidalgo-Blanco, Á., et al., Using Learning Analytics to improve teamwork assessment. Computers in Human Behavior, 2015. 47: p. 149-156. 
[12] Ahad, A.D. and S.M.A. Lim, Convenience or nuisance?: The 'WhatsApp'dilemma. ProcediaSocial and Behavioral Sciences, 2014. 155: p. 189-196.

[13] Sultan, A.J., Addiction to mobile text messaging applications is nothing to "lol" about. The Social Science Journal, 2014. 51(1): p. 57-69. 